\section{SOI: $1.1 /$ TAS DOI: $10.15863 /$ TAS International Scientific Journal Theoretical \& Applied Science}

p-ISSN: 2308-4944 (print)

e-ISSN: 2409-0085 (online)

Year: 2015

Issue: 09

Volume: 29

Published: 30.09 .2015

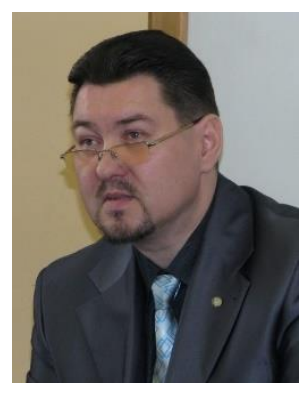

Oleg Borisovich Molodov

Candidate of historical sciences,

Institute of Socio-Economic

Development of Territories of RAS

Vologda, Russia

o_young8172@mail.ru

SECTION 24. Sociological research.

\title{
TRANSFORMATION OF LANGUAGE SPACE OF THE COUNTRIES OF CENTRAL ASIA AND TRANSCAUCASIA
}

\begin{abstract}
The article presents the results of a comparative study of linguistic space of the countries of Central Asia and Transcaucasia. It is based on the results of the sociological polls, statistical materials and publications devoted to the ethnic and linguistic transformations in post-Soviet space.

Key words: linguistic space, national language, official language, Russian language, ethnic identification, Central Asia, Transcaucasia.

Language: Russian

Citation: Molodov OB (2015) TRANSFORMATION OF LANGUAGE SPACE OF THE COUNTRIES OF CENTRAL ASIA AND TRANSCAUCASIA. ISJ Theoretical \& Applied Science 09 (29): 58-62.

Soi: http://s-o-i.org/1.1/TAS-09-29-14 Doi: crossef http://dx.doi.org/10.15863/TAS.2015.09.29.14

\section{ТРАНСФОРМАЦИЯ ЯЗЫКОВОГО ПРОСТРАНСТВА СТРАН ЦЕНТРАЛЬНОЙ АЗИИ И ЗАКАВКАЗЬЯ}

Аннотация: В статье представлень результаты сравнительного исследования языкового пространства стран Центральной Азии и Закавказья. Она основана на результатах сочиологических опросов, статистических материалах и публикаций, посвященных этническим и лингвистическим трансформациям на постсоветском пространстве.

Ключевые слова: языковое пространство, начиональный язык, официальный язык, русский язык, этническая идентификация, Центральная Азия, Закавказье.
\end{abstract}

Языковое пространство - это прочный, устойчивый ареал распространения того или иного языка, в первую очередь как родного и официально закрепленного на определенной территории [15, c. 152].

Несмотря на единую предысторию в пространстве бывшего СССР, после распада страны языковая ситуация в каждой республике стала отличаться определенной спецификой. Однако общей чертой во всех государствах постсоветского пространства стало ощутимое сокращение числа владеющих русским языком.

В советский период происходило выстраивание этноцентрического государства с ориентацией на доминирующую нацию - русскую. Это привело, в первую очередь, к русификации городов, где представители «европейских национальностей» составили своего рода профессиональную элиту [2, с. 25].

Объективными предпосылками для этого стали: утверждение статуса государственного языка за титульными национальными языками, сокращение количества этнических русских как основных носителей русского языка и культуры, а также переориентация молодежи на знание европейских языков и языков крупных стран регионального окружения.

Как представляется, динамика интеграции находится во взаимосвязи с этническими и языковыми процессами в Центральной Азии (ЦА) и Закавказье. В частности, русский язык признан официальным в государствах ЦА, имеющих значительную долю русскоязычного (в основном русского по национальности) населения, которая в настоящее время составляет в Казахстане 21,5\%, в Кыргызстане - 6,5\%. Именно они являются членами всех межгосударственных объединений наряду с Российской Федерацией. Наименьшую вовлеченность в интеграционные процессы демонстрируют Узбекистан, где около 2\% русских, и Туркменистан (3,2\%). Там русский язык законодательно признан языком межнационального 
общения, но его значение в сфере науки и образования невелико.

После распада СССР демографические и миграционные процессы в этих странах привели к значительным изменениям их национального состава [18, с. 102-103]. За 25 лет суверенитета в Казахстане резко сократилась доля славянского населения (русских и украинцев), немцев и татар более чем на 4 млн. чел. При этом численность казахов увеличилась на 4,7 млн. жителей. Доля русских, составлявших в 1989 г. 38\%, сократилась до $22 \%$ от общего числа жителей [1].

По данным статистики видно, что сходные процессы происходили в соседнем Кыргызстане, где представители титульной нации в настоящее время составляют три четверти населения республики [12]. Вместе с тем, доля русских, по нашим подсчетам, сократилась в 3 раза, украинцев - в 8 раз, немцев - в 12 раз, татар - в 31 раз [9, c. 96$]$.

К субъективным предпосылкам можно отнести, во-первых, неблагоприятные политические условия для распространения русского языка, ухудшение которых связывают с началом «украинского кризиса» 2014 года. С другой стороны, проблема статуса русского языка в Украине лежит в основе продолжающегося конфликта. Во-вторых, сократилось количество русскоязычных образовательных учреждений и ухудшилось их материальное положение. Оплотом на постсоветском остаются учрежденные совместно с Россией «Славянские» университеты: Кыргызско-Российский (КРСУ), РоссийскоТаджикский, Российско-Армянский и Белорусско-
Российский, где обучаются около 20 тыс. студентов, две трети из который - по российским образовательным программам.

В качестве предмета изучения русский язык постепенно от родного или второго родного языка переходит к иностранному языку, изучаемому факультативно (в странах Балтии, Азербайджане, Грузии, Туркменистане). Искусственные ограничения русскоязычных коммуникационных ресурсов заметны в Украине, Туркменистане, Грузии и Молдове. По мнению аналитиков, позиции русского языка надежно обеспечиваются только в Беларуси, где он остается государственным языком и доминирует в СМИ.

Результаты опросов общественного мнения в странах постсоветского пространства (без стран Балтии и Туркмении) показали, что нуждаются в знании русского языка: для работы $15 \%$ респондентов, для просмотра кинофильмов и телепередач - 19\%. Почти все опрошенные (96\%) высказали желание, чтобы их дети знали русский язык, так как владение им считается важным преимуществом [17]. По данным на 2011 г., признают себя свободно владеющими русским языком 90\% жителей Казахстана, 66\% - Армении, $60 \%$ - Кыргызстана, 45\% - Грузии и только 23\% Азербайджана (таблица 1). Предпочитают общение на нём в основном жители Казахстана и Кыргызстана.

Владение русским языком в странах СНГ (по данным Института Gallup 2011 г.) [17]

\begin{tabular}{|l|c|c|c|}
\hline \multicolumn{1}{|c|}{ Страна } & $\begin{array}{c}\text { Владеют } \\
\text { русским языком (\%) }\end{array}$ & $\begin{array}{c}\text { Из них } \\
\text { свободно (\%) }\end{array}$ & $\begin{array}{c}\text { Предпочитаемый язык } \\
\text { общения - русский (\%)* }\end{array}$ \\
\hline Казахстан & 99,9 & 89,6 & 68 \\
\hline Узбекистан & 99,2 & 85,3 & - \\
\hline Армения & 93,3 & 66,3 & 38 \\
\hline Кыргызстан & 87,1 & 60,5 & 7 \\
\hline Грузия & 78,4 & 44,8 & 6 \\
\hline Азербайджан & 70,1 & 22,8 & 5 \\
\hline Таджикистан & 68,5 & 41,2 & \\
\hline * По данным опросов 2007 г. &
\end{tabular}

Данные этого исследования демонстрируют значительный разрыв между желаниями и возможностями респондентов.

То есть в Казахстане и Кыргызстане русский язык еще находится на достаточно высоком уровне. Однако в Азербайджане $47 \%$ опрошенных признают, что «очень плохо понимают русскую речь», в Грузии таких более $25 \%$, в Таджикистане $12 \%$.

Казахский язык, обладая статусом государственного, функционирует в основном в казахской этнической среде и так и не стал языком межэтнической коммуникации [11, с. 46]. Русские и другие национальные меньшинства страны не хотят, чтобы русский язык и другие их привычные 
символы ушли на периферию нового общества [6, c. 41] Нативизация (казахизация) сталкивается с сильными позициями русского языка и русскосоветской культуры, обретенными еще в советский период и продолжающими доминировать в силу инерционности культурных процессов [7, с. 60].

Русский язык намного чаще звучит в городе, поэтому есть стимул изучать его для карьерных целей. Вместе с тем, казахоязычие стало основным средством социальной коммуникации для тюркоязычных народов страны (узбеков, азербайджанцев, турок, уйгуров, дунган). Позиции казахского языка укрепляются в связи с миграцией «оралманов» - этнических казахов-репатриантов из соседних стран, которые не владеют русским языком [5, с. 102]. Золотухин С.А. отмечает, что в последние годы русскоязычные родители стали отдавать детей в дошкольные учреждения с воспитателями-казахами в целях освоения разговорного языка титульной нации.

В советский период на территории Армянской ССР сложилась уникальная билингвальная среда, нехарактерная для мононационального состава населения, поскольку в республике 90\% жителей составляли армяне. Почти половина населения равноценно владела армянским и русским языками, при этом нередки были случаи доминирования последнего. Эта ситуация имела место благодаря проводимой языковой политике, хорошо разработанной методической базе преподавания русского языка в средней и высшей школах и наличию в Армении высококвалифицированных специалистов-русистов [4, с. 96].

Количество и доля жителей Армении, признавших русский язык родным [16]

\begin{tabular}{|c|c|c|c|c|c|c|c|}
\hline & \multirow{2}{*}{$\begin{array}{c}\text { Общее число } \\
\text { жителей } \\
\text { (чел.) }\end{array}$} & \multirow{2}{*}{$\begin{array}{c}\text { Признали } \\
\text { русский язык } \\
\text { родным (чел.) }\end{array}$} & \multirow{2}{*}{$\begin{array}{c}\text { Доля } \\
\text { от общего } \\
\text { числа } \\
\text { жителей } \\
(\%) \\
\end{array}$} & \multicolumn{2}{|c|}{$\begin{array}{c}\text { Доля } \\
\text { по признаку пола } \\
(\%) \\
\end{array}$} & \multicolumn{2}{|c|}{$\begin{array}{c}\text { Доля } \\
\text { по месту } \\
\text { проживания (\%) }\end{array}$} \\
\hline & & & & муж. & жен. & город & село \\
\hline РА в целом & 3018854 & 23434 & 0,8 & 33,8 & 66,2 & 75,8 & 24,2 \\
\hline \multicolumn{8}{|l|}{ из них: } \\
\hline армяне & 2961801 & 11861 & 0,4 & 36,9 & 63,1 & 82,7 & 17,3 \\
\hline украинцы & 1176 & 357 & 30,4 & 19,3 & 80,7 & 89,9 & 10,1 \\
\hline русские & 11911 & 10466 & 87,9 & 31,3 & 68,7 & 67,1 & 32,9 \\
\hline греки & 900 & 88 & 9,8 & 21,6 & 78,4 & 86,4 & 15,6 \\
\hline ассирийцы & 2769 & 81 & 2,9 & 30,9 & 69,1 & 58,0 & 42,0 \\
\hline грузины & 617 & 75 & 12,2 & 28,0 & 72,0 & 93,3 & 6,7 \\
\hline езиды & 35308 & 79 & 0,2 & 35,4 & 64,6 & 48,1 & 51,9 \\
\hline
\end{tabular}

Несмотря на то, что русский язык признали родным менее одного процента населения, его реальный статус гораздо выше правового. Не претендуя на роль государственного языка, он продолжает оставаться в Армении языком межнационального общения и межкультурной коммуникации: им свободно владеют около $70 \%$ жителей [4, с. 99].

В Таджикистане, несмотря на норму статьи 2 Конституции 1994 г., закон «О государственном языке» №553 от 5 октября 2009 г. первоначально не содержал указания на статус русского языка как языка межнационального общения. Однако, учитывая сложившуюся практику большинства государственных органов вести делопроизводство на русском языке, 9 июня 2011 г. этот статус был возвращен [3].

По данным переписи населения, в Таджикистане число русских к 2010 году сократилось в 11 раз, а их доля составила всего 0,5\%. Количество таджиков выросло более чем в два раза, а их доля вместе с узбеками (второй по численности нации) достигла 96,5\% [13]. Материалы данной переписи показывают, что значение русского языка в качестве второго, которым жители владеют свободно, для национальных меньшинств невелико. При сопоставлении показателей владения таджикским и русским языками видно, что государственный язык сохраняет приоритет и в качестве языка межнационального общения. В частности, таджикским языком свободно владеют 52\% узбеков (русским - 10\%), 31\% кыргызов и туркменов (русским - по 11\%). Важно учесть, что узбеки, кыргызы и туркмены составляют в совокупности более 1 млн. жителей страны (около 16\%). Только среди татар, численность которых по результатам переписи всего 6,5 тыс. чел., доля свободно владеющих русским языком вдвое больше, чем таджикским (45 против 23\%) [10].

Распространение русского языка в советский период происходило как под влиянием 
геополитических факторов, в результате действия административных методов, так и за счет целенаправленной государственной политики СССР по предоставлению образовательных услуг иностранным студентам. Около 1 млн. человек получили дипломы советских вузов [8 с. 99].
В настоящее время в вузах России также обучаются студенты из зарубежных стран, причем две трети из них приходится на государства Центральной Азии (табл. 4).

Численность иностранных граждан, обучавшихся в вузах России [16, с. 19, 26]

\begin{tabular}{|l|c|c|c|c|}
\hline \multirow{2}{*}{ Страна } & \multicolumn{2}{|c|}{$2012 / 2013$ учебный год } & \multicolumn{2}{c|}{ 2013/2014 учебный год } \\
\cline { 2 - 5 } & $\begin{array}{c}\text { Доля от } \\
\text { Количество } \\
\text { студентов (чел.) } \\
\text { общего числа } \\
\text { иностранных } \\
\text { студентов (\%) }\end{array}$ & $\begin{array}{c}\text { Количество } \\
\text { студентов (чел.) }\end{array}$ & $\begin{array}{c}\text { инострона } \\
\text { студентов (\%) }\end{array}$ \\
\hline Армения & 4934 & 7,1 & 5479 & 6,8 \\
\hline Азербайджан & 2058 & 3,0 & 2639 & 3,3 \\
\hline Грузия & 936 & 1,3 & 977 & 1,2 \\
\hline Казахстан & 23656 & 33,9 & 27524 & 34,0 \\
\hline Кыргызстан & 2627 & 3,8 & 3591 & 4,4 \\
\hline Таджикистан & 5660 & 8,1 & 6561 & 8,1 \\
\hline Туркменистан & 10954 & 15,7 & 12114 & 15,0 \\
\hline Узбекистан & 5605 & 8,0 & 6288 & 7,8 \\
\hline
\end{tabular}

Примечательно, что треть от общего числа иностранных студентов являются гражданами Казахстана, территориально примыкающего к границам РФ и в наибольшей степени вовлеченного в интеграционные процессы в рамках СНГ, ЕАЭС и Таможенного союза. Однако более одной пятой части студентов-иностранцев представляют Туркменистан и Узбекистан - государства, проявляющие более независимую политику, в том числе и в языковой сфере.

C одной стороны, абсолютные показатели численности студентов-иностранцев дают возможность надеяться, что будущие выпускники российских вузов, вернувшись на родину, смогут преумножить роль и значение русского языка в своих государствах. С другой стороны, статистические данные не позволяют уточнить, какова среди них доля представителей русскоязычного меньшинства, получающего в России образование на родном для них языке.
Важным представляется и то, что получение российского диплома об образовании повышает шансы будущих специалистов остаться работать в России или Казахстане, активно принимающих трудовых мигрантов из соседних стран.

Исследование показало, что несмотря на сокращение этнолингвистического пространства русского языка, наибольшие шансы для сохранения его на постсоветском остаются у Республики Казахстан. Важными предпосылками для этого стали: значительная доля русскоязычного населения, официальный статус русского языка и последовательная политика интеграции с Россией. Как представляется, постепенная изоляция отдельных стран Центральной Азии и Закавказья от достижений русской культуры, образования и научного знания препятствует дальнейшим интеграционным процессам в регионе, а также легализации и получению достойного места работы трудовыми мигрантами.

\section{References:}

1. (2014) Agentstvo Respubliki Kazahstan po statistike. Seriya 15. Demografiya. Chislennost' naseleniya Respubliki Kazahstan po otdel'nym ehtnosam na nachalo 2014 g. Astana, 2014.
2. Bejshenbaeva AR (2015) «Tradicionalizm» i «modernizm» kyrgyzskoj identichnosti // Strategiya. 2015. № 1 (3). pp. 19-31.

3. (2014) V Tadzhikistane russkomu yazyku vernuli prezhnij status // Available: 


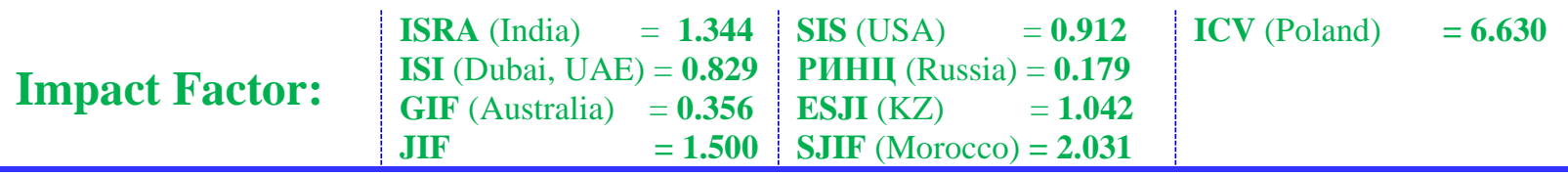

www.Lenta.ru/news/2011/06/09/Russian (Accessed 20.06.2014).

4. Dashyan N (2012) Status russkogo yazyka i problemy bilingvizma v Armenii // Slovo.ru: Baltijskij akcent. 2012. Vyp. 2. pp. 96-99.

5. Zolotuhin SA (2012) Osobennosti adaptacii russkih v Kazahstane // Socis. 2012. № 2. pp. 99-103.

6. Kadyrzhanov R (2012) Problemy issledovaniya ehtnokul'turnogo simvolizma i nacional'noj identichnosti Kazahstana // Adam əlemi-Mir cheloveka. 2012. № 3 (53). pp. 34-41.

7. Kadyrzhanov R (2013) Social'no-politicheskie problemy kazahskogo yazyka i ehtnokul'turnyj simvolizm Kazahstana // Adam əlemi-Mir cheloveka. 2013. № 2 (56). pp. 53-62.

8. Medvedeva TA (2014) Znachenie yazykovogo faktora $\mathrm{v}$ sovremennom mire // Latinskaya Amerika. 2014. № 8. pp. 97-107.

9. Molodov OB (2014) Problemy identifikacii naseleniya Kazahstana i Kyrgyzstana // Socium i vlast'. 2014. № 6 (50). pp. 95-102.

10. Molodov OB (2015) Russkij yazyk v stranah Central'noj Azii: sravnitel'nyj aspekt // Aktual'nye problemy mnogoyazychiya $\mathrm{v}$ Respublike Uzbekistan: materialy respublikanskoj nauchno-prakticheskoj konferencii. - Fergana: FGU, 2015. pp. 44-49.

11. Narbekova G (2012) Nacional'noe stroitel'stvo i kul'turnaya identichnost' Kazahstana // Adam əlemi-Mir cheloveka. 2012. № 3 (53). pp. 4350.

12. (2014) Nacional'nyj statisticheskij komitet Kyrgyzskoj respubliki // Available: http://stat.kg/ (Accessed 20.07.2014).

Available: (Accessed: 20.09.2015).

et al.
13. (2012) Nacional'nyj sostav, vladenie yazykami i grazhdanstvo naseleniya Respubliki Tadzhikistan. T. 3. Dushanbe: Agentstvo po statistike pri Prezidente Respubliki Tadzhikistan, 2012. $-537 \mathrm{p}$.

14. (2014) Obuchenie inostrannyh grazhdan v vysshih uchebnyh zavedeniyah Rossijskoj Federacii: statisticheskij sbornik. Vyp. 11. Moscow: Centr sociologicheskih issledovanij, 2014. -200 .

15. Purynycheva GM, Shagaeva MI (2011) Yazykovoe prostranstvo Rossii: metodologicheskij analiz // Vestnik Chuvashskogo universiteta. 2011. № 1. pp. $150-154$.

16. (2013) Rezul'taty perepisi naseleniya Respubliki Armeniya 2011 g. Erevan: Nacional'naya statisticheskaya sluzhba RA, 2013.

17. (2015) Russkij yazyk v Srednej Azii i Zakavkaz'e dolgo ne proderzhitsya // Available: http://www.iarex.ru/articles/34194.html (Accessed 2.07.2015).

18. (2009) Sociokul'turnye aspekty razvitiya territorii / A. A. Shabunova, K.A. Gulin, N.A. Okulova [i dr.]. Vologda: ISEHRT RAN, 2009. $-130 \mathrm{p}$. 